\title{
The economic implications of exaptation ${ }^{\star}$
}

\author{
Nicholas Dew ${ }^{1, \star \star}$, S.D. Sarasvathy ${ }^{2}$, and S. Venkataraman ${ }^{3}$ \\ 1 Graduate School of Business and Public Policy, Naval Postgraduate School, \\ Monterey, CA 93943, USA \\ 2 R.H. Smith School of Business, University of Maryland, College Park, MD 20742, USA \\ 3 Darden Graduate School of Business Administration, University of Virginia, \\ Charlottesville, VA 22906, USA
}

\begin{abstract}
Accounts of economic change recognize that markets create selective pressures for the adaptation of technologies in the direction of customer needs and production efficiencies. However, non-adaptational bases for technological change are rarely highlighted, despite their pervasiveness in the history of technical and economic change. In this paper the concept of exaptation - a feature co-opted for its present role from some other origin - is proposed as a characteristic element of technological change, and an important mechanism by which new markets for products and services are created by entrepreneurs. Exaptation is a missing but central concept linking the evolution of technology with the entrepreneurial creation of new markets and the concept of Knightian uncertainty.
\end{abstract}

Key words: Exaptation - Evolution - Adaptation - Entrepreneurship - Knightian uncertainty

JEL Classification: O3, M13, D8, D52

\section{Introduction}

Despite their pervasiveness, many phenomena go unrecognized and un-researched for long periods of time. The management theorist Karl Weick uses the example of battered child syndrome (BCS), which was first suggested in 1946 by John Caffrey, a pediatric radiologist who noticed a pattern of injuries invisible to the naked eye but visible on X-rays (Weick, 1995, pp. 1-2). Caffrey's report was based on six

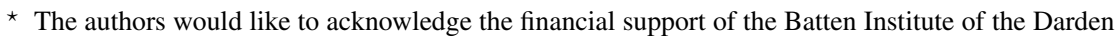
School of Business Administration, University of Virginia, for carrying out this research. We also wish to thank Rama Velamuri and an anonymous referee for their comments, which significantly improved this paper. All remaining faults are the sole responsibility of the authors.

$\star \star$ Correspondence to: N. Dew (e-mail: ndew@nps.navy.mil) 
case histories of young children whose parents' accounts of the child's history were silent about how the injuries occurred. However, it was not until 1961 that BCS became an observable phenomenon "out there" in the world, after a panel at the American Academy of Pediatrics annual meeting and the publication of the panel's findings in the Journal of the American Medical Association, which was based on hundreds of reported cases accumulated nationwide. Like many phenomena, BCS was invisible, unknown and ignored until it was named and elevated as an issue. Moreover, such phenomena are often bundled with other associated phenomena and remain unattended to by researchers for as long as they are obscured in a broader taxonomy. This can result in incoherent theoretical accounts, with important theoretical insights badly matched with empirical phenomena organized in conflicting taxonomies. It can also result in limiting the range of hypotheses available for testing.

This paper addresses one such phenomenon in the literature on economic and technical change - the phenomenon of exaptation. An exaptation is a feature coopted for its present role from some other origin. Exaptations are pervasive in the history of technology and markets (Mokyr, 2000), a point we will illustrate with some examples in the account that follows. This paper will show how exaptations are an important part of what entrepreneurs do, and cause, and that identification of this phenomenon helps makes sense of empirical phenomenon in technological and economic change that have received relatively little attention, such as the genesis of new markets. Despite the pervasiveness of exaptations in economic and technological development, the subject has to date been relegated to a provincial role in discussions of change. In this paper we hope to illustrate why exaptations are, in fact, a central issue in technological and economic change. This paper describes what exaptations are and why they are important.

The paper is organized as follows. First, different meanings of adaptation are discussed and exaptation is defined. Second, three examples of exaptations - some of them well known in the literature on technological change - are explicated in order to illustrate the concept in concrete terms. Third, the economic implications of exaptation are explained, in particular the important link between exaptation, uncertainty and profits. The paper ends with a conclusion that highlights main themes and implications. The whole paper can be summarized in three succinct points, which represent the core ideas of the paper:

1. Exaptations - features of a technology co-opted for their present role from some other origin - are a central and pervasive phenomenon in the development of technology over time and, as such, are an important phenomenon in any theory of economic change. A strong focus on the adaptation of technology products and processes to user needs and efficiency criteria has generally obscured the phenomenon of exaptation, which points to the non-adaptive origins of many technologies, and the process by which they are later co-opted for other roles.

2. The ordering of events in technological history is important, and exaptation is one concept that points to process issues that are material to the pattern of change and development of technologies. Unlike biological systems where the timing of adaptations may be immaterial, in economic systems the costs of creating information means it makes all the difference in the world if a technology has 
already been developed and can be exapted from a prior use to a new domain of use. The relative costs of produ cing and using information therefore suggests that the normal pattern of technology development ought to show frequent sideways exaptations of technologies fueling gradual adaptive development of a technology. Exaptation therefore suggests swapping lineage for breadth as a key researchable phenomenon of technological development. Since the key agent of exaptation is the entrepreneur, the concept of exaptation also suggests a central role for entrepreneurship in the development of technology, puttin $g$ the "pilot" (Cohendat et al., 1999) back accounts of the development of technology in ways that accord with both common observation, empirical research and prior theoretical accounts.

3. The concept of exaptation points up the fact that the functions a technology is selected for are only a subset of its causal consequences, and that no finite limit exists to the exaptive potential of a given technology, be that product (artifact) or process (technique). The lack of the ability to pre-state all possible product and service markets has the familiar ring about it of the phenomenon Frank Knight (1921) pointed to as the true causal locus of profits and the contractual organization of the f irm - what we now call Knightian uncertainty. Exaptation is thus shown to be a missing but central concept that links the development of technology, the entrepreneurial creation of new markets and the concept of Knightian uncertainty.

\section{The evolutionary process}

The term exaptation was originally coined in evolutionary biology, in an article addressing missing terminology in the science of form (Gould and Vrba, 1982). Gould and Vrba noticed that the concept of adaptation in fact subsumes two different criteria: historical genesis and current use. The first meaning of adaptation historical genesis - refers to the dynamic process of evolutionary adaptation where an organism is "designed" by adaptation for fitness in a specific function, task or application. Consistent with all well-received evolutionary theories, the notion of fitness used here does not refer to the "survival of the fittest" in some global sense but is merely a measure of advantage along key parameters of the match between organism and environment that lead to a species having a higher likelihood of reproductive success. For instance, in the case of artifacts, the Romans found that bronze swords were not well fitted to their desired role as they were prone to bend in the cut and thrust of close quarters battle; as a result they experimented with different metallurgy until they produced swords of superior functionality by virtue of having a better balance between flexibility and rigidity. Such instances represent conscious design efforts to adapt form to function (well) along certain key parameters that were crucial to success. In nature the Darwinian algorithm of the overproduction of progeny with random variations and their elimination by environmental selection is generally thought to exert the same pressures towards adaptation as the battlefield did for the Roman sword. Both of these processes - Lemarkian directed design or design by natural selection - refer to historical processes that change natural and manmade artifacts in the direction of functional adaptation. The key idea is that 
adaptation is a matter of design for a task, whether that occurs through variationselection-retention processes or Lemarkian learning processes (Nelson and Winter, 1982). This led Williams (1966, p. 6) to define adaptation as occurring when we can, "attribute the origin and perfection of this design to a long period of selection for its effectiveness in this particular role." (emphasis added).

The second meaning of adaptation - current utility - defines adaptation in a static way. This conception of adaptation takes any feature that currently enhances fitness to be an adaptation, regardless of the evolutionary process by which it developed. Economic perspectives that take equilibrium concepts as central to the analysis use the term adaptation in this way. But this concept is actually better described by the term "aptation" rather than adaptation, since the etymology of "aptus" is "fit", whereas "adaptus" refers to the process of increasing fitness by designing for a particular function.

\section{Defining exaptation}

These two meanings of adaptation - historical genesis and current use - roughly correspond to the division of labor between researchers who study economic processes of change over time using dynamic and historical frameworks, and those that study economic processes through in a static equilibrium framework. The resulting confusion in the meaning of adaptation can be resolved by making the taxonomy of evolutionary processes more complete by introducing the concept of exaptation (Gould and Vrba, 1982). As Mokyr describes exaptation: "The basic idea is that a technique that was originally selected for one trait owes its later success and survival to another trait which it happens to possess." (Mokyr, 2000, p. 57). As Table 1 illustrates, we can define an adaptation according to some clear-cut criteria, as a feature of an artifact or technique that was built for the purpose of fitness in a particular role. The operation of an adaptation is its function, and functions posi-

Table 1. Taxonomy of fitness (Gould and Vrba, 1982, p 5)

\begin{tabular}{|l|l|l|l|}
\hline Process & \multicolumn{2}{|l|}{ Definition } & Usage \\
\hline $\begin{array}{l}\text { Natural selection } \\
\text { processes shape a } \\
\text { characteristic for } \\
\text { current use }\end{array}$ & Adaptation & Aptation & Function \\
\cline { 1 - 1 } $\begin{array}{l}\text { An characteristic } \\
\text { previously shaped } \\
\text { for another function } \\
\text { is co-opted for } \\
\text { a new use }\end{array}$ & Exaptation & Effect \\
\cline { 1 - 2 } $\begin{array}{l}\text { A character whose } \\
\text { origin cannot be } \\
\text { ascribed to selection } \\
\text { processes is } \\
\text { co-opted for use }\end{array}$ & & \\
\hline
\end{tabular}


tively selected for their fitness are by definition adaptations. Operations not built by selection for a particular role can be designated as effects. These effects, which initially evolved for other reasons (for example, owing to design constraints) or for no identifiable reason at all (Gould, 2002) are defined as exaptations when they are later co-opted for a new role. In their historical genesis exaptations were not designed for their current use and therefore were not adaptations because they were not pushed towards fitness by evolutionary processes. Instead, these features later turned out to be fit for a new role by virtue of their effects, rather than by virtue of their original design.

A classic example of a technical innovation that illustrates both the process of adaptation and of exaptation is the compact disk. Originally developed in the late 1960s at the Pacific Northwest National Laboratory in Richland, WA, like most inventions the compact disk was an adaptive design for a specific task: solving the problem of poor sound quality and wear and tear suffered by vinyl phonograph records. Its inventor, James T. Russell, developed the system based on the idea of using light as a medium because he envisioned a system that would record and replay sounds without physical contact between its parts. The CD-ROM was therefore patented in 1970 as a digital-to-optical recording and playback system. However, researchers at the lab with large quantities of experimental data exapted CD-ROM technology for another use: a data storage medium for computers. This was a function the CD-ROM was not designed for, but one that later, nevertheless, it proved very effective for. As a result, during the 1970s the lab refined CD-ROM technology for any form of data, and set the stage for the eventual commercialization of the technology both the music and computing industries.

\section{What exaptations are not}

It is important to be clear about what exaptations are not as, like any other pervasive phenomenon, they are otherwise apt to be confused with other phenomenon and misdiagnosed. First of all, many economists might recognize some affinity between the concept of exaptation and the concept of externalities, which are generally defined as "The effect of one person's decision on someone who is not a party to that decision." (Coase, 1988). The difference between the two concepts is that exaptation is a phenomenon that is related to context changes that happen over time, and is not amenable to analysis at a point in time. Exaptations are the effects of technologies that are later co-opted for their usefulness. By contrast, externalities are not rooted in changes in context.

Second, exaptations are not another way of describing the entrepreneurial process of creatively combining existing ideas (Schumpeter, 1934). Schumpeter's suggestion that entrepreneurs creatively assemble existing ideas into something new has generally been taken to mean that entrepreneurs combine two or more distinct technologies (Levinthal, 1998, p. 220). Exaptation instead points to a different phenomenon, one that depends on context changes that change the utility of technologies. Exaptation therefore thrives on acts such as connecting a technology with a new domain of use - in other words, on technology-domain combinations, not on technology-technology combinations. Indeed the combination of technology and 
new domain of use is "a quintessential entrepreneurial activity." (Levinthal, 1998, p. 220).

Third, many researchers might suggest that exaptations are simply unintended consequences of technologies. However, this ignores the fact that the act of exapting a technology normally requires deliberate leveraging of effects of a technology that would otherwise have been dormant or perhaps gone unnoticed. Effects that are exapted may, after the fact look like unintended consequences of the original design of the technology, but one organization's "unintended consequences" only exist because an entrepreneur has put those effects to work by exapting them.

Finally, basic research often gives rise to inventions that initially are designed without a use in mind, and therefore cannot be called adaptive in the first place. One widely quoted study from the 1970 s found that $41 \%$ of all basic scientific inventions and discoveries had no immediate use, but that over long periods (around 25 years) these discoveries were converted to useful ends (Comroe, 1977). As such these basic inventions fall into a category of exaptables as a case of technologies that are not created because of their immediate functionality. The concept of exaptation merely points up with more precision that the operative principle of such research endeavors is explicitly non-adaptive.

So, to recap, the difference between today's adaptive functions (and/or unintended/random consequences) and tomorrow's exaptable effects marks off the critical distinction between adaptations that arise as a result of selection processes and effects - things caused, produced, results or consequences - that were not initially designed for, but represent a pool of tools available for later co-optation by exaptation.

\section{Reasons for exaptations}

Exaptations may have three possible origins. First, they may have been adaptations to prior circumstances - in other words, actively selected in for the task at hand. For instance, compact disk technology was an active adaptation. Second, they may have been features that were selected in as part of a bundle of features, but in-and-of themselves made no particular contribution to the performance of the technology. In other words, they were neutral or immaterial in regard to the selection regime. For instance, vitrification, a process originally developed for environmental remediation (mainly the safe processing of high level radioactive waste), is proving to be eminently exaptable for processing biological hazards (such as hospital wastes and even destroying stocks of biochemical weapons) owing to the fact that the extremely high temperatures utilized in the process kill most biological agents. Third, technological features may have been constraints unavoidably selected in as part of a bundle of features, even though the particular feature was a negative drain on performance of the whole. For instance, in the post World War Two period innovations in plastics production were largely based on utilizing unwanted byproducts of petroleum refining processes. 
This structure of exaptive possibilities follows from two characteristics of artifacts, whether those are natural, artificial or social in nature ${ }^{1}$. The first is near decomposability. In his original exposition of the architecture of complexity, Simon (1996) pointed to the fact that complex systems such as those observed in technology have a structure that is best described as nearly decomposable: that is, they display a hierarchical structure where the overall structure of an artifact is decomposable into subparts and the subparts display short-run behaviors that are approximately independent of the short run behavior of other subparts. Over the long run the behavior of components depends on the aggregate behavior of the other components. As a result, sub-optimal subpart design is one of the pervasive features of technologies, but these subparts are selected and proliferate by virtue of being only one aspect of the entire artifact, and the entire artifact may display adaptive characteristics. Indeed, non-adaptive subparts within an adaptive whole are usually taken as a sure sign of a hierarchical architecture (Axelrod and Cohen, 1999). More recent research into modular design (Langlois and Robertson, 1992; Schilling, 2000) illustrates the same point: designers select the overall best technological solution for the problem at hand, but every solution has more and less optimal features. As a result, the raw material for future exaptations is everywhere.

A second characteristic of technologies that suggests the later exaptation of possibilities is the lack of a finite list of causal consequences of a technology in its context. Unexpected features of everyday life bear testimony to this deep philosophical point - that the list of possible descriptions of any object in context is infinite. Parochial examples abound of objects being used in previously unimaginable ways (as any traveler can attest from a visit to a foreign land far removed from the norms of her homeland). Famous examples include the creativity displayed in crises, including the multiple creative exaptations that the Apollo 13 ground crew came up with to save the crew drifting in space with a dwindling oxygen supply.

To summarize, technologies are typically aggregates of subparts and one cannot know in advance all the uses that some oddball subpart of a technology might have in some oddball situation sometime in the future. Primarily this is a practical matter in the development of technology, but this phenomenon also has a sound philosophical basis. Sometime in the future, such a technology will clearly have not been designed to be adaptive to the situation, but will have been co-opted as an exaptation anyway.

\section{Examples of exaptation}

\section{Edison and the phonograph}

According to the account related by the technology historian Basalla (1988), Edison's invention of the phonograph in 1877 appears to represent an archetype of the exaptive possibilities created by a new technology. The basic technology can only

1 Social artifacts would include the socially complex routines (Nelson and Winter, 1982) or techniques (Mokyr, 1990) which are often taken as the basic unit of selection in theorizing about evolutionary processes in economic systems. These routines and techniques are almost always confederations of subroutines or sub-techniques organized hierarchically. 
be described as fully pregnant with possibilities, and its immediate uses were by no means self-evident. Edison, who owing to his own deafness consistently directed his inventive genius towards technologies that amplified and reproduced sound, invented the phonograph with a mind to recording dictations for later reproduction. Basalla recounts that in 1878 Edison published an article specifying ten possible ways in which the invention might be useful to the public:

"He suggested that it be employed to take dictation without the aid of a stenographer; provide "talking books" for the blind; teach public speaking; reproduce music; preserve important family sayings, reminiscences and the last words of the dying; create new sounds for music boxes and musical toys; produce clocks capable of announcing the time and a message; preserve the exact pronunciation of foreign languages; teach spelling and other rote material; and record telephone calls. This listing is important because it represents Edison's own order of priority for the potential uses of his talking machine.” (Basalla, 1988, pp. 139-140).

Needless to say, Edison chose to sell the phonograph to the market he had designed it for: to business offices as a dictating machine. He persisted in marketing the phonograph for this use for ten years. Frustrated at times by the lack of progress in commercializing the technology, at one point in the early 1880s Edison declared that the technology had no commercial value at all. Since Edison regarded the technology as a serious invention, he resisted all application of the technology to domains of use that, in his mind, trivialized his invention. Of course, it was therefore left to other entrepreneurs to exapt the technology to a new domain of use. The exaptation was the primitive jukebox, which co-opted the phonograph from its origin as a dictation device to a new role - automatically playing popular music in public places with the deposit of a coin. The jukebox, which became the first major use of Edison's new technology, of course never appeared on Edison's list of uses, even though the exaptation was in retrospect obvious, something that was further underlined by the immense popularity of the new device. Yet no one could have predicted this rather context dependent consequence of Edison's new technology, which initially proved useful in the odd public environment of funfairs and seaside resorts as a novelty attraction. Like all artifacts, the jukebox came to be as a creature of its context, and then stayed for a while.

Also like most exaptations, the jukebox followed the familiar pattern of being initially technologically conservative in that it primarily drew on the features that were inherent in Edison's technology and available for exploitation given context changes created by switching the technology into a different domain of use (Levinthal, 1998). Jukeboxes then took up an development trajectory all of their own, being gradually adapted to perform better given the demands of their selection environment, and perhaps occasionally making a technical contribution to the exaptive pool of possibilities constituted by the general technological paradigm of phonography. Of course, by popularizing phonograph technology and creating a need for a stream of freshly recorded new music, the jukebox laid down the basis of an eventual new industry - the music industry. 
For his part, in 1891 - fourteen years after the invention of the phonograph - Edison still staunchly refused to accept the jukebox as a legitimate use of phonographic technology, because he believed that it detracted from his efforts to establish the phonograph as the technology of choice for dictation in the serious domain of the business office. Only in the mid-1890s did Edison come to accept that the primary use of the phonograph would be for entertainment purposes, after the technology had reached widespread acceptance in the public's eye in the form of the jukebox.

Curiously, history does have a habit of repeating itself. According to Basalla (1988, p. 140), one might have expected that the lessons of the phonograph would have served as a guide to the budding Tokyo Telecommunications Company (later Sony) as it attempted to introduce the tape recorder after World War Two. Tape recording technology was originally developed during the war as part of the German war effort, but Sony noted its eminently exaptable qualities and quickly developed the technology for the public domain, initially selling it to Ministry of Justice courts as a device for recording court proceedings, and to universities and schools for the teaching of languages. Clearly Sony's sometimes lauded intuition for mating technologies with use domains was somewhat clouded in the case of the tape recorder, for at one point the firm produced a pamphlet listing 999 possible uses of the tape recorder in its search for a market. It wasn't until the 1960s that tape technology was exapted to a new domain of use - primarily tapes for playing pre-recorded music - after which sales of the new device took-off, with 8 tracks being responsible for bringing pre-recorded music, long known in the household in the form of the phonograph, to mobile transport: the automobile. Once again we see that the context change that a new domain of use represented led to a creative exaptation of technological features that were non-obvious in prior contexts. The rest - including the Walkman, which was another exaptation - is history.

\section{The laser}

Historical accounts suggest that the laser is another technology with a development history full of exaptations. Without using the term "exaptation”, Rosenberg (1996) recounts how the laser has been co-opted for numerous new roles. The name laser, an acronym derived from "light amplification by stimulated emission of radiation, describes how a laser beam is produced. A product of fundamental scientific research, the underlying science was worked out by Einstein in a paper produced in 1916 (Rosenberg, 1996) but the invention of the laser is attributed to Charles H. Townes, who shared a Nobel prize for his pioneering work on the laser in the early 1950s. The first working laser was constructed in 1960 by Theodore Maiman, since which time the laser has been exapted into a wide range of applications. Among those exaptations are the following:

- Microsurgery: such as remedying detached retinas, tumor removal and gallbladder surgery. In the case of retinal surgery, accidents and the disease retrolental fibroplasia can both cause retinal detachment, which causes permanent blindness without prompt treatment. Surgeons use a procedure that applies heat with a laser beam to cause scarring that prevents the retina from detaching again. 
- Precision measurement: a good example is the laser rangefinder, which is used to measure the distance from the instrument to a selected point. Developed in 1965, the laser rangefinder has largely replaced optical range finders for surveying and replaced radar in some military applications.

- Bomb guidance systems: an innovation related to the laser rangefinder. Laserguided weapons follow a laser beam trained on the target by an independent targeter. These so-called "smart bombs" are steered by fins on the bomb that move in response to the laser guide.

- The barcode: the now familiar Universal Product Code (UPC) is a printed series of parallel bars of varying width and spacing that is "read" by a laser scanner that feeds the data into a computer system. Barcodes are widely used for identifying objects in manufacturing, distribution and retailing systems.

- Holography: splits a laser beam, with half the beam falling unaltered onto a recording medium (ex: a photographic plate) and the other half reflected off an object. Together, the two beams produce a pattern of interference on the plate that creates a holographic image.

- For cutting, drilling and welding materials: lasers are widely used for cutting textiles, metals and composite materials. In welding, laser welding is one of several new processes to be recently developed for this two-millenium year-old innovation.

- The aforementioned compact-disc player: the disk is "read" optically by a lowpowered laser, along similar lines as reading barcodes, and the data fed to a computer for processing.

- In publishing: where laserjet printing is one of the most common printing methods in use.

- The SDI (strategic defense initiative): commonly known as "Star Wars", SDI was launched in 1983 to defend the U.S. from a nuclear missile attack. SDI proposed to use lasers to shoot down missiles while in flight. In 1999 the U.S. announced a renewed effort to implement this anti-missile defense program.

- Telecommunications: finally, Rosenberg draws attention to the important exaptation of the laser into telecommunications, where it is used in fiber optic cables. The use of lasers in telecommunications was so unforeseen that Bell Labs were initially unwilling even to apply for a patent on the technology. According to the laser's inventor, Charles Townes: "Bell's patent department at first refused to patent our amplifier or oscillator for optical frequencies because, it was explained, optical waves had never been of any importance to communications and hence the invention had little bearing on Bell system interests." (Townes, 1968, p. 701; cited by Rosenberg, 1996, p. 93).

Rather like the phonograph, the laser is a technology that has been the raw material for a stream of exaptations that leaves little doubt as to the role of exaptation in the history of technological evolution. The effects of the laser, which originally served no purpose at all, have been co-opted for productive new roles in a pattern of exaptation that Rosenberg (1996, p. 93) describes as "truly breathtaking" and "still in the early stages." 


\section{The architecture of agricultural tractors}

A simple but illustrative example of exaptation in the agriculture industry is recounted by Kauffman (2000). Late in the nineteenth century, engineers struggled to invent the tractor. Typical of many important but simple insights, the idea of agricultural equipment powered by the internal combustion engine was fairly obvious to many individuals and organizations, but operationalizing the technology proved troublesome. The Charter Gasoline Engine Company of Sterling, IL, first successfully mated an internal combustion engine to a Rumley steam-traction-engine chassis in 1889, producing six of the machines, making Charter the first producer of the "tractor". Of course, taking the internal combustion engine to the agricultural industry was a clear domain shift for the technology which, in principle, was an attractive replacement for the prevalent power source of ages: animal power. But engines with suitable power outputs were large and heavy, so much so that they buckled the tractor chassis. And engineers developing the technology knew that the weight of the tractor was unattractive to farmers because heavy equipment compacts soil, and compacted soil typically reduces crop yields.

So the engineers, for all their efforts, appeared to be at a dead end. Then, at some point in time, somebody suggested that, as the engine block was so huge and so rigid, why not use the engine, coupled with the equally heavy and complex gearbox and drive axle components, as the chassis of the tractor. The front axle, ancillary equipment and drivers seat could be attached to the engine-gearbox-axle arrangement, which would be the chassis itself, allowing the engineers to dispense with a separate chassis, and a lot of weight as a result. Thus the chassis of a tractor is actually an exaptation of the engine-gearbox-axle equipment that was necessary to make the tractor a tractor in the first place. Once the exaptation was produced, it was of course widely imitated by all producers, becoming the standard architecture for the tractor industry up to the present day.

The architectural exaptation of the tractor engine provides a good example of the way a domain shift changes the salient features of a technology in ways that were non-obvious beforehand. Indeed, the lesson of such a shift is that it might, per the phonograph and tape recorder example, be illustrative of other "hidden" structural features of a technology and become a template for other domain shifts and exaptations. Putting the internal combustion technology into a different domain of application and re-contextualizing its function resulted in the features of the technology being harnessed for useful purposes in a very different way than had been conceived in other domains of application.

\section{Significance of exaptation}

\section{Exaptation, uncertainty and profits}

The nature of exaptation suggests that one cannot pre-state a finite list of all possible exaptations of the myriad of technologies that exist in the world. We cannot predict ahead of time what the list might look like, even if we had knowledge of the complete array of technologies and artifacts that presently exist in the world, as we cannot 
predict all of the context dependent ways in which some subpart of a technology might have a use in some situation sometime in the future. Indeed, the history of technology is full of examples of technologies that, just like the laser, were initially thought to be of no value at all. Citing many examples, Rosenberg (1996, p. 95) concludes that, "This listing of failures to anticipate future uses and larger markets for new technologies could be expanded almost without limit."

This lack of the ability to pre-state all possible products and services has the familiar ring about it of the phenomenon Frank Knight (1921) pointed to as the true causal locus of profits and the contractual organization of the firm - what is now well known in the literature as "Knightian uncertainty". This suggests some coherence and integration between Knight's ideas and exaptation.

To briefly recap Knight's reasoning, which has received several fine treatments in the literature (Langlois and Cosgel, 1993; Boudreaux and Holcombe, 1989), Knight pointed to a typology of uncertainties, under the guise of risk (situations amenable to estimation by statistical analysis), uncertainty (situations amenable to Bayesian updating of probabilities based on learning about the environment) and true uncertainty (Knightian uncertainty, which is not amenable to probabilistic calculation). Knight suggested risk and uncertainty were in principle always insurable, and therefore could never be the source of profits. True uncertainty, however, would never be insurable as nobody could know in advance what to write the insurance contract for. Knight therefore suggested true uncertainty was the cause of all profits, and necessitated the contractual structure of the firm, where residual profits are owned by the stockholders whose equity in the firm "insured" other stakeholders with whom the firm had contracts.

The concept of exaptation, which suggests the impossibility of pre-stating a complete array of markets, therefore ties the concept of Knightian uncertainty to something very concrete and observable in the world. One of the regular debates about Knightian uncertainty is whether it should be taken as axiomatic and, if not, what concrete experiences in the world suggest that we should care about the phenomenon of Knightian uncertainty? Theorists often turn to Popperian arguments (Popper, 1958) about the consequences of fundamental scientific discoveries and inventions, which create a stream of fundamental uncertainties, thus impoverishing predictions of the future based on present and past data. Therefore exogenous events are called upon to provide the underlying reasoning behind Knight's argument for the third type of uncertainty. Excellent though this argument is, our thesis here is that exaptation provides a complimentary endogenous explanation. It is a conceptually clear and empirically observable phenomenon that logically implies Knightian uncertainty. Exaptation thus connects Knightian uncertainty to concrete events in the world thus affirming the efficacy of Knight's idea by linking it to the development of new technology and new markets.

\section{New markets, primary exaptation and secondary adaptation}

The development of technologies and markets is often a messy affair spanning tens of years. The concept of exaptation helps delineate this process in finer detail by suggesting a pattern of adaptation and exaptation at work in the evolution of 
technologies that together contribute to the set of aptations present at any one time. First, technology genesis occurs by adaptation to a pre-existing domain of use or via discoveries and inventions from basic research; second, primary exaptations occur where the technology branches off by being linked to a new domain of use; next, secondary adaptations develop the technology based on the selection criteria of the new market; and lastly, technical developments in one branch of the technology then feedback to the broader industry using the technology. Therefore, the aptations existing at any one time is made up of two partially overlapping subsets: one subset is the subset of adaptations and the other is the subset of exaptations (Gould and Vrba, 1982, p. 6).

In a study of the development of wireless communications technology, Levinthal (1998) points to this adaptation-exaptation pattern as wireless technology developed from initial applications in wireless telegraphy to broadcast radio to wireless telephony. Each successive exaptation resulted in the creation of a new industry, yet was initially based on extremely modest technological shifts - classic exaptations of features that were developed in one domain but also proved to have useful effects in the context of other domains. For instance, it took Westinghouse a matter of a few weeks and a few thousand dollars to develop a consumer broadcast radio set for the mass market. Subsequent development of wireless in each of these industries proceeded by better adapting the technology to the specific domain of use, based on feedback from the domain, but also indirectly contributed to the pool of technology available for future exaptations, which included paging devices, television and radio frequency identification devices. Simple initial technical exaptations typically prefigured more important technical developments with significant commercial impact.

One of the implications of Levinthal's study is that, unlike biological systems where the timing of adaptations may be immaterial, in economic systems the costs of creating information means it makes all the difference in the world if a technology has already been developed and can be exapted from a prior use to a new domain of use. As long ago pointed out by Arrow (1962) the indivisibility of information means that while technology is expensive to create, the costs of reusing it are marginal and often close to zero. So while the absence of a market for new products creates substantial uncertainty that undermines already risky investments in research to produce new technology, the low cost of reusing existing technologies makes these technologies an attractive basis for cooptation into new domains of application. Firms endeavoring to develop new markets confront a frighteningly long list of uncertainties: will buyers adopt the new product and, if so, over what time frame?; will the technology work and be produced at the price point required to make a sale? (usually determined by substitutes/alternatives); and will the firm be insulated enough from competitors to get a return on its up-front investments? (usually determined by several isolating mechanisms: speed to market, patent protection, secrecy, complimentary assets, barriers). Non-existent markets do not generally support extensive research and development of technologies, suggesting that the normal pattern of technology development ought to show frequent sideways exaptations of technologies fueling gradual adaptive development of a technology in a particular domain. The phenomenon of exaptation therefore suggests swapping 
a research focus on the lineage of a technology for a focus on its breadth of use by examining its branching into new markets through a process of exaptation.

One of the questions such a pattern raises is the genesis of the exapted technology. The history of any technology will likely show a sequential mixture of initial development through adaptation followed by primary exaptations and secondary adaptations. Most new technologies will have their genesis in adaptive processes going on in other domains of use: military demands drove several of the major technologies in the post World War Two era - including integrated circuits, aeronautics and nuclear power (Hooks, 1990; Cowan, 1990). In studies of industrial innovations, von Hippel (1988) has shown that most innovations are initially developed by users as adaptive solutions to particular problems, and then commercialized separately. Much original software development proceeds this way - i2 Technologies finite scheduling software for manufacturing plants is a good example of this (i2 Technologies 2002). And Christensen (2000) has shown that in the computer disk drive industry technologies which were developed on an adaptive (and often exploratory) basis but rejected as inferior are sometimes exapted off the research bench into new domains of use in which they later develop very successfully. Indeed, these low cost technologies became "disruptive" when market needs converged or the technology developed to the point of being general purpose. A pattern of "creative destruction" (Schumpeter, 1976) sometimes followed, with the best technology invading other niches, sometimes including the one from which it originally was exapted (Levinthal, 1998).

Therefore, exaptation compliments suggestions that much technology development proceeds along paradigmatic lines, within an established trajectory (Dosi, 1983) and often as an industry standard (Tushman and Anderson, 1990). These arguments suggest that technologies accumulate much change gradually via adaptive processes - qualities the CD-ROM, tractor and jukebox all display. However, each of these technologies also bears witness to the process of exaptation in its developmental history, a point that has received less attention in the literature on technological and economic change.

\section{Concluding observations}

Exaptation - using things for purposes other than those for which they were designed - is a pervasive feature of economic change. We suspect that many scholars of technological evolution can readily name several examples of exaptation from their own research. According to Mokyr, "[I]n the history of technology, exaptation is probably more common than in natural history. Many of the most dramatic inventions of the modern age were originally selected for purposes that were quite different from what eventually turned out to be their most enduring trait." (Mokyr, 2000). ${ }^{2}$ While this assertion awaits broader testing, this article has made some initial efforts to clarify the concept of exaptation and explain its implications.

2 Within the literature on evolutionary biology the concept of exaptation has had a mixed reception. Neo-Darwinist thinkers, as summarized by Dennett (1995), have rejected the concept. The concept has proved more robust among paleontologists (perhaps suggesting exaptation is most useful in explaining macro-level change) and among biologists that study the evolution of the human brain (where it has 
The usefulness of the concept of exaptation lies in clarifying an evolutionary process that currently lacks a clear conceptual "bucket". The interpretation of evolutionary processes is simplified when the concept of exaptation is recognized. For biologists, for instance, the concept of exaptation makes sense of the evolution of flight, which depends on understanding how feathers developed for one reason (temperature regulation) but were later exapted for another use (flight). Similarly, in the evolution of a technology sector such as pharmaceuticals, exaptation makes sense of the persistent pattern of products that are originally selected for one trait owing their later success to another trait. The unanticipated uses of Aspirin, Viagra and Rogaine are all examples of the exaptation of effects that these drugs were not initially selected for. ${ }^{3}$

In conclusion, a picture (in the form of a mental image) is often worth a thousand words, so consider the many technological analogies to Kauffman's flying squirrel story:

"A particularly ugly squirrel named Gertrude was atop a tree $65,433,872$ years ago. She was ugly because she had folds from her forearms stretching to her hind limbs. So ugly was Gertrude that she was shunned by the other squirrels and was sadly alone atop a magnolia tree eating lunch. But just yards away, high in a pine, was Bertha, an owl. Bertha spotted Gertrude and thought, "Lunch!" Bertha flashed downward through shafts of light toward Gertrude. Gertrude looked suddenly up and was terrified. "GAAAAAAH," she cried and jumped in desperation from the top of the magnolia tree, flinging her arms and legs wide in terror. And yes, Gertrude flew! Yes, she flew away from the magnolia tree, eluding the bewildered Bertha. Later that month, Gertrude was married ... Her odd flaps turned out to be a consequence of a simple Mendelian gene, hence her kids had the same wondrous capacity to fly. And that is how flying squirrels got their wings, more or less." (Kauffman, 2000, p. 131).

The phonograph, laser and tractor chassis all display the same characteristic of being technologies whose effects were exaptable in much the same way as skin folds in flying squirrels. Rather like ugly ducklings, some technologies have a propensity to be transformed by exaptation into white swans.

proven useful in explaining the development of several human capabilities - imagination, for example). Gould uses the term extensively in his work, including his magnum opus, The Structure of Evolutionary Theory (2002).

3 Rosenberg (1996) reports that Aspirin was in use for nearly a century as an analgesic before its efficacy as a blood thinner was recognized. As a result of its blood-thinning properties, aspirin is now used to reduce the incidence of heart attacks. Viagra was originally developed as a heart disease treatment, but during trials patients reported that the drug also had a useful side effect, which led to Viagra being launched as a drug that alleviates impotence. Rogaine also had an indirect origin, before eventually being found to increase hair growth. It subsequently established the market for hair growth products, in which it remains the leader. 


\section{References}

Arrow KJ (1962) Economic welfare and the allocation of resources for inventions. In: Nelson R (ed) The rate and direction of inventive activity. Princeton University Press, Princeton, NJ

Axelrod RM, Cohen MD (1999) Harnessing complexity : organizational implications of a scientific frontier. Free Press, New York

Basalla G (1988) The evolution of technology. Cambridge University Press, Cambridge, MA

Boudreaux DJ, Holcombe RG (1989) The coasian and knightian theories of the firm. Managerial and Decision Economics 10: 147-154

Christensen C (2000) The innovator's dilemma. Harvard Business School Press, Cambridge

Coase RH (1988) The firm, the market and the law. University of Chicago Press, Chicago

Cohendet P, Llerena P, Marengo L (1999) Is there a pilot in the evolutionary firm? In: Foss N, Mahnke VP, Mahnke V (eds) Competence, governance, and entrepreneurship: advances in economic strategy research. Oxford University Press, Oxford

Comroe JH (1977) Retrospective: insights into medical discovery. Von Gehr Press, Menlo Park, CA

Cowan R (1990) Nuclear power reactors: a study of technological lock-in. The Journal of Economic History 50(3): 541-567

Dennett D (1995) Darwin's dangerous idea. Simon and Schuster, New York

Dosi G (1983) Technological paradigms and technological trajectories. Research Policy 11: 147-162

Fisher RA (1958) Genetical theory of natural selection. Dover, New York

Gould SJ, Vrba ES (1982) Exaptation - a missing term in the science of form. Paleobiology 8(1): 4-15

Gould SJ (2002) The structure of evolutionary theory. Belknap, Cambridge, MA

Hooks G (1990) The rise of the Pentagon and U.S. state building: the defense program as industrial policy. American Journal of Sociology 96: 358-404

i2 Technologies (2002) website: www.i2technologies.com

Kauffman S (2000) Investigations. Oxford University Press, New York

Knight FH (1921) [1957] Risk, uncertainty, and profit, 8th edn. Kelley and Millman, New York

Langlois RN, Cosgel MM (1993) Frank Knight on risk, uncertainty, and the firm: a new interpretation. Economic Inquiry: 31, 456-465

Langlois RN, Robertson PL (1992) Networks and innovation in a modular system: lessons from the microcomputer and stereo component industries. Research Policy 21(4): 297-313

Levinthal DA (1998) The slow pace of rapid technological change: gradualism and punctuation in technological change. Industrial and Corporate Change 7: 217-247

Mokyr J (1990) The lever of riches: technological creativity and economic progress. Oxford University Press, New York

Mokyr J (2000) Evolutionary phenomena in technological change. In: Ziman J (ed) Technological innovation as an evolutionary process, pp 52-65. Cambridge University Press, Cambridge

Nelson R, Winter S (1982) An evolutionary theory of economic change. Harvard University Press, Cambridge

Popper KR (1957) The poverty of historicism. Beacon Press, Boston

Rosenberg N (1996) Uncertainty and technological change. In: Fuhrer JC, Sneddon Little J (eds) Technology and growth. Conference Series No.40. Federal Reserve Bank of Boston, Boston

Schilling MA (2000) Towards a general modular systems theory and its application to inter-firm product modularity. Academy of Management Review 25: 312-334

Schumpeter JA (1934) The theory of economic development. Harvard University Press, Cambridge

Schumpeter JA (1976) Capitalism, socialism and democracy. Harper and Row, NY

Simon HA (1996) The architecture of complexity. In: Sciences of the Artificial, 3rd edn. MIT Press, Cambridge

Townes CH (1968) Quantum mechanics and surprise in the development of technology. Science (February) 159: 699-703

Tushman ML, Anderson P (1990) Technological discontinuities and dominant designs: a cyclical model of technological change. Administrative Science Quarterly 35(4): 604-634

Von Hippel E (1988) The sources of innovation. Oxford University Press, New York

Weick K (1995) Sensemaking in organizations. Sage, Thousand Oaks, CA

Williams GC (1966) Adaptation and natural selection. Princeton University Press, Princeton 
Copyright of Journal of Evolutionary Economics is the property of Springer Verlag New York, Inc. and its content may not be copied or emailed to multiple sites or posted to a listserv without the copyright holder's express written permission. However, users may print, download, or email articles for individual use. 
Copyright of Journal of Evolutionary Economics is the property of Springer Verlag New York, Inc. and its content may not be copied or emailed to multiple sites or posted to a listserv without the copyright holder's express written permission. However, users may print, download, or email articles for individual use. 